\title{
DIALÉTICA DO \\ DESENVOLVIMENTO PERIFÉRICO: \\ DEPENDÊNCIA, SUPEREXPLORAÇÃO DA FORÇA \\ DE TRABALHO E POLÍTICA ECONÔMICA*
}

\author{
Marcelo Dias Carcanholo
}

RESUMO Este trabalho procura discutir as possibilidades de desenvolvimento na periferia da economia mundial, enfatizando dois aspectos. Em primeiro lugar, observa-se que as políticas econômicas neoliberais e a reestruturação produtiva foram formas encontradas pelo capital para responder à sua própria crise dos anos 1970, e que essas formas aprofundaram a condição de dependência das economias periféricas dentro da lógica mundial de acumulação capitalista. Em segundo lugar, constata-se que a única maneira de desenvolvimento capitalista na periferia, tendo em vista o aprofundamento da dependência, é a superexploração da força de trabalho. Por fim, argumenta-se que as alternativas para a periferia passam pela redução dessa superexploração da força de trabalho e/ou da luta contra a própria exploração capitalista da força de trabalho como forma de extração de excedente.

Palavras-chave: economia mundial; dependência; superexploração da força de trabalho; desenvolvimento periférico

Código JEL: B51, F02 e O10

\section{DIALECTICS OF PERIPHERAL DEVELOPMENT: DEPENDENCE, SUPEREXPLOITATION OF LABOR FORCE AND ECONOMIC POLICY}

ABSTRACT This paper aims to discuss the possibilities of development in the periphery of the world economy emphasizing two points. Firstly, there is that the neo-

\footnotetext{
* Artigo recebido em 28 de junho de 2007 e aprovado em 30 de junho de 2008.

** Professor Adjunto da Faculdade de Economia da Universidade Federal Fluminense, e-mail: mdcarc@uol.com.br
} 
liberal economic policies and productive restructuring were forms found by capital to respond to its own crisis of 70's, and that these forms deepened the condition of dependency of peripheral economies within the logic of global capitalist accumulation. Secondly, it appears that the only way of capitalist development in the periphery, with a view to deepening dependence, is the superexploitation of labor force. Finally, it is argued that the alternatives to the periphery are the reduction of superexploitation of labor force and/or the fight against the capitalist exploitation of the labor force as a form of extraction of surplus.

Key words: world economy; dependence; superexploitation of labor force; peripheral development 


\section{INTRODUÇÃO}

É impossível entender a lógica contemporânea de acumulação de capital em escala mundial sem observar a crise do capitalismo nos últimos 40 anos, assim como as respostas encontradas por ele na tentativa de recompor as condições de uma acumulação ampliada.

No início dos anos 1970, o capitalismo volta a apresentar um comportamento cíclico que algumas correntes teóricas chegaram a advogar como extinto. ${ }^{1}$ Depois da Segunda Guerra Mundial, e com o estabelecimento do Welfare State, não foram poucos os analistas que interpretaram os "anos gloriosos" como uma tendência estrutural que tinha vindo para ficar. Os anos 1970 se encarregaram de contrariá-los e lembrar o caráter inerentemente cíclico da acumulação capitalista.

As crises cíclicas do capitalismo são o resultado do desenvolvimento das suas próprias contradições. São o momento de irrupção da contradição entre a produção de mercadorias e a realização dos valores produzidos e, ao mesmo tempo, de recomposição da unidade contraditória entre os dois pólos, produção e realização (apropriação - circulação). A recomposição da unidade é justamente o restabelecimento das condições de valorização, a partir das próprias conseqüências da crise, e, portanto, o que fornece à crise uma característica cíclica.

Sendo assim, as mesmas leis de funcionamento do modo de produção capitalista levam a uma produção ilimitada de mercadorias, no impulso de acumulação ampliada, a um consumo (demanda) abundante, na medida em que sua expansão leva consigo a dos mercados, e à constituição de barreiras à realização do valor produzido. Essas barreiras impedem que a maior demanda consiga realizar o crescente valor produzido. O que constrói essas barreiras e, portanto, se constitui na causa das crises é a contradição entre o caráter social da produção e a característica privada da apropriação capitalista. $^{2}$

Dessa forma, as crises capitalistas se definem como uma superacumulação, isto é, uma superprodução de capital incapaz de continuar obtendo seus níveis de lucratividade anteriores. Superprodução de capital e redução da taxa de lucro são características das crises de superacumulação de capital. Além do mais, essas duas características, dado o processo de concorrência intercapitais, provocam uma expansão da concentração/centralização do 
capital, que se transforma em um crescimento da composição orgânica média do capital (produtividade média), reforçando o efeito de redução da taxa de lucro do sistema. As crises cíclicas do modo de produção capitalista têm esse comportamento. Foi exatamente isso - ainda que com formas de manifestação específicas — o que ocorreu nos anos 1970. ${ }^{3}$

Uma análise mais apressada poderia pensar que o primeiro sinal da crise nos anos 1970 ocorre com a elevação do preço do petróleo, entre outubro de 1973 e janeiro de $1974 .{ }^{4}$ Nesse período, o preço do petróleo mais do que triplica, passando de US\$ 3,5 por barril de petróleo bruto para US\$ 11,65 por barril. A economia mundial, entretanto, já dá o sinal da reversão cíclica antes disso. Ainda que o biênio 1974-1975 seja claramente o momento culminante da crise, em que as economias passam a apresentar inclusive taxas negativas de crescimento, ${ }^{5}$ é de se destacar que Estados Unidos, em 1970 ( $-0,1 \%$ de taxa de crescimento), e Alemanha Ocidental, em 1971 (3,2\% de crescimento, em face de $6 \%$ do ano anterior), já mostravam fortes retrações econômicas.

Os dados, sistematizados em Mendonça (1990, p. 45), sobre a taxa de crescimento na formação bruta de capital fixo, isto é, do ponto de vista de incremento de capital como decorrência do processo de acumulação, ainda que apenas no que diz respeito ao componente fixo do capital constante, confirmam essa reversão cíclica. O biênio 1974-1975 concentra os efeitos da crise. Entretanto, merecem destaque o incremento negativo de capital fixo na economia americana já no ano $1970(-4,7 \%)$, sua expressiva retração em $1975(-11,2 \%)$ e a virada cíclica no conjunto dos países da OCDE, que apresentava acumulação de capital crescente no período 1970-1973 (3,7\% em $1970,4,6 \%$ em 1971, 6,4\% em 1972 e 7,3\% em 1973), e rapidamente se retrai no biênio $1974-1975$ (-4,8\% em 1974 e -5,3\% em 1975).

Ainda é preciso destacar que, embora a crise cíclica da economia mundial tenha começado na virada dos anos 1960 para os anos 1970, os seus efeitos foram agravados pela crise do padrão monetário vigente na época (padrão dólar-ouro) - em um sentido mais amplo, pela própria desmontagem do sistema de Bretton Woods - a partir da decisão americana de decretar, unilateralmente, a inconversibilidade do dólar em ouro em 1971. Essa medida mostrou-se necessária como uma forma de preparar a iniciativa de desvalorização do dólar (que começa em 1973), para, de algum modo, 
compensar as perdas da economia americana, em termos de competitividade internacional. ${ }^{6}$

Como se deu a resposta do capital? De que forma a lógica mundial de acumulação capitalista foi reposta?

Viu-se que a crise dos anos 1970-1980 apresentou as características de redução nas taxas de lucro e superprodução do capital. A resposta à primeira característica teve um duplo aspecto. Em primeiro lugar, como os investimentos não eram expandidos em função da baixa lucratividade, conforme a argumentação convencional e algumas mais heterodoxas, tratava-se de garantir a recomposição dessa lucratividade em três frentes. Por um lado, era necessário reduzir os custos salariais, consideravelmente elevados nos tempos de Welfare State. Por outro lado, demandou-se a redução da tributação sobre investimentos, ou melhor, sobre os rendimentos que podem financiar investimentos, os lucros. Adicionalmente, implementou-se um processo de reestruturação produtiva baseado na aceleração da rotação do capital, de forma que, para um mesmo período, fosse possível a ampliação da produção do excedente, mantendo-se o volume de capital aplicado, o que eleva as taxas de lucro nesse período. ${ }^{7}$ Por isso, a resposta do capital a esse primeiro aspecto de sua própria crise foi: (i) pressão por desregulamentação e flexibilização dos mercados, em especial do mercado de trabalho; (ii) política tributária regressiva, desonerando os altos rendimentos; e (iii) redução do tempo de rotação do capital.

O outro aspecto da crise, a superprodução de capital, significava que existia um excesso de capital que não conseguia valorização nos moldes "tradicionais", isto é, através da produção crescente de mercadorias, com posterior venda/realização em mercados também crescentes. Era preciso encontrar outra esfera para que esse capital produzido em excesso conseguisse valorizar-se. Não é por acaso que os processos de desregulamentação, abertura e internacionalização das finanças tenham sido acelerados nesse momento. A expansão do capital fictício, dentro do que alguns chamam de financeirização, em busca da apropriação financeira cada vez menos baseada no processo direto de produção de mercadorias, é a resposta do capital a esse outro aspecto de sua própria crise. ${ }^{8}$

Em resumo, a tentativa de recuperação da acumulação de capital no centro do sistema passa por quatro aspectos: (i) recuperação da lucratividade dos investimentos; (ii) redução no tempo de rotação do capital; (iii) trans- 
ferência de recursos da periferia; e (iv) expansão dos mercados para fronteiras além do centro da acumulação mundial.

A partir dos anos 1980 a tentativa de recuperação da acumulação em escala mundial ganhou esses contornos. A transferência de recursos da periferia para o centro ganhou maior roupagem com a crise da dívida externa nos países periféricos, crise esta que se alastrou nos anos 1990, e com a remessa de lucros e dividendos que os capitais transnacionais realizaram das filiais na periferia para as matrizes no centro. ${ }^{9}$ Já a expansão dos mercados está inserida na pressão pela abertura comercial, principalmente dos mercados periféricos, em processos como o Nafta e a Alca.

Assim, enquanto o processo de reestruturação produtiva se encarregou da rotação do capital, o neoliberalismo, como aspecto político, ideológico e econômico, teve o papel de garantir as condições de lucratividade interna (desregulamentação e flexibilização dos mercados - principalmente o de trabalho) e externa (pressão por desregulamentação e abertura dos mercados comerciais e financeiros). Na verdade, reestruturação produtiva e neoliberalismo são duas interfaces de uma mesma resposta do capital à sua própria crise nos anos 1970.

Essa resposta à crise dos anos 1970 perpassa a década de 1980, atinge seu ápice nos anos 1990 e mantém sua influência hegemônica no século XXI. Neoliberalismo, expansão do capital fictício, transferência do excedente produzido na periferia para o centro (em especial para os EUA) são as marcas da década de 1990 que se mantêm neste início de século.

E a periferia? Existem condições de desenvolvimento periférico em uma situação de brutal remessa de excedente para o centro da acumulação mundial?

\section{ACUMULAÇÃO DE CAPITAL NA PERIFERIA: DESENVOLVIMENTO VERSUS SUBDESENVOLVIMENTO}

Costuma-se entender como economia periférica aquele país, ou região, que apresenta, em geral, instáveis trajetórias de crescimento, forte dependência de capitais externos para financiar suas contas-correntes (fragilidade financeira), baixa capacidade de resistência diante de choques externos (vulnerabilidade externa) e altas concentrações de renda e riqueza. Isso caracterizaria o subdesenvolvimento dessas economias. ${ }^{10}$ 
A percepção convencional, a partir dessa constatação factual, tende a conceber a situação de subdesenvolvimento como sendo equivalente à ausência de desenvolvimento, isto é, como um "atraso" em relação às experiências históricas de desenvolvimento. Assim, seria possível extrair modelos de desenvolvimento das experiências de economias avançadas, com a definição de estágios que pudessem superar o atraso e atingir a modernidade. Mesmo concepções um pouco mais críticas, como a visão clássica da Cepal, entenderam desenvolvimento e subdesenvolvimento como fenômenos quantitativamente diferenciados, podendo resolver o segundo com medidas corretivas, no plano do comércio internacional, e por uma política econômica adequada, que dependeria das situações concretas vivenciadas pela economia mundial. ${ }^{11}$

Restrição ao crescimento, fragilidade financeira, vulnerabilidade externa e perfil concentrado de renda e riqueza seriam, dessa forma, anomalias das economias periféricas, passíveis de correção por arranjos internacionais e/ou políticas econômicas adequadas, ortodoxas ou não, dependendo da filiação teórica dos proponentes.

O que esse tipo de perspectiva não consegue captar é que desenvolvimento e subdesenvolvimento são fenômenos qualitativamente diferenciados e ligados tanto pelo antagonismo como pela complementaridade, ou seja, que, embora sejam situações antagônicas, os dois fenômenos pertencem à mesma lógica/dinâmica de acumulação de capital em escala mundial.

A dialética do desenvolvimento, assim percebida, concebe que o subdesenvolvimento de alguns países/regiões resulta precisamente do que determina o desenvolvimento dos demais. A lógica de acumulação de capital em escala mundial possui características que, ao mesmo tempo, produzem o desenvolvimento de determinadas economias e o subdesenvolvimento de outras. É para essa dependência dos países periféricos, em face da acumulação de capital, centrada em determinadas regiões, que a teoria da dependência chamou a atenção. ${ }^{12}$

A partir dessa perspectiva, todas as características de uma economia periférica, citadas anteriormente, possuem um caráter estrutural, determinado pela própria condição de dependência, não passível de superação/solução pelo mero manejo "adequado" do instrumental de política econômica.

O conceito de dependência, assim entendido, implica uma situação em que uma economia está condicionada pelo desenvolvimento e expansão de 
outra a que está subordinada, isto é, a condição de subdesenvolvimento estaria conectada estreitamente à expansão dos países centrais. Essa condição, portanto, representaria uma subordinação externa, mas com manifestações internas nos "arranjos" social, político e ideológico. ${ }^{13}$

Marini (1977, p. 18) sintetiza o significado da dependência:

...relación de subordinación entre naciones formalmente independientes, en cuyo marco las relaciones de producción de las naciones subordinadas son modificadas o recreadas para asegurar la reproducción ampliada de la dependencia.

Isso não é o equivalente à constatação óbvia, e quase tautológica, da interdependência entre as diversas economias no cenário mundial. Quando essa interdependência implica o país dominante expandir-se (crescer) auto-sustentadamente, enquanto os outros só o fazem como reflexo dessa expansão, tendo efeitos positivos e negativos no seu desenvolvimento, definese a condição de dependência. Dessa forma, o subdesenvolvimento não seria um primeiro estágio de evolução rumo à modernidade desenvolvida, mas, ao contrário, característica antagônica e complementar do processo de desenvolvimento dentro de uma mesma lógica global de acumulação capitalista. ${ }^{14}$

\subsection{Condicionantes da dependência e superexploração da força de trabalho}

Entendendo assim o desenvolvimento e o subdesenvolvimento como um par dialético, têm-se os dois fenômenos como qualitativamente diversos ao invés de uma mera diferenciação quantitativa, contornável através da superação de estágios de desenvolvimento - e marcados pelo antagonismo e a complementaridade. Antagonismo justamente por se tratar de situações distintas dentro da lógica de acumulação capitalista mundial, mas complementares por serem necessariamente elementos constitutivos dessa lógica.

De um ponto de vista esquemático, e correndo todos os riscos reducionistas desse tipo de procedimento, é possível identificar três condicionantes histórico-estruturais da dependência: (i) o fato empírico recorrente de perda nos termos de troca, ou seja, a redução dos preços dos produtos exportados pelas economias dependentes — geralmente produtos primários e/ou com baixo valor agregado - em face dos preços dos produtos industriais 
e/ou com maior valor agregado importados dos países centrais, em um verdadeiro processo de transferência de valores; (ii) a remessa de excedentes dos países dependentes para os avançados, sob a forma de juros, lucros, amortizações, dividendos e royalties, pela simples razão de os primeiros importarem capital dos últimos; (iii) a instabilidade dos mercados financeiros internacionais, geralmente implicando altas taxas de juros para o fornecimento de crédito aos países dependentes e colocando os países dependentes periféricos à mercê do ciclo de liquidez internacional.

Marini (1977) procura explicar os mecanismos de transferência de valor inerentes ao condicionante (i) a partir de dois lados. Em primeiro lugar, operam os mecanismos internos a uma mesma esfera de produção. Como as mercadorias tendem a ser vendidas a partir do valor de mercado, isto é, do valor referente às condições médias de sua produção (produtividade média), e os países dependentes possuem padrões de produtividade inferiores aos países do centro, ocorre a transferência de valor excedente (mais-valia extra) da periferia para o centro por conta do processo de concorrência entre os capitais externos e internos, dentro de uma mesma esfera de produção. Em segundo lugar, opera o processo de concorrência entre distintas esferas de produção. Esse processo de concorrência reflete a entrada e saída de capitais de várias esferas, conforme as diferentes taxas de lucro vigentes nessas esferas, o que tende a igualar as taxas de lucro. Entretanto, o monopólio de produção de mercadorias com maior valor agregado no centro faz com que os capitais externos possam vender seus produtos a um preço que supera aquele que prevaleceria com iguais taxas de lucro, definindo também um mecanismo de transferência de valor. Esses dois mecanismos operam dentro do condicionante (i) de dependência.

Adicionalmente, dada a característica atual de aprofundamento da desregulamentação e abertura financeira, deve-se ressaltar o funcionamento de outro mecanismo de transferência de valor, além daquele próprio do comércio internacional de mercadorias. O capital externo, na forma de investimento direto, tende a repatriar lucros e dividendos, e, portanto, remete valor criado na periferia para o centro. Por outro lado, na sua forma de endividamento, implica a transferência de valor a partir do pagamento de juros e amortizações de dívida. Por fim, a dependência tecnológica também coloca a transferência de valor produzido na periferia para o centro na forma de pagamento de royalties. 
De um ponto de vista histórico, pode-se afirmar que, do período précapitalista até a consolidação inicial do modo de produção capitalista, os países desenvolvidos extraíam o excedente produzido na periferia através da expropriação, dentro da acumulação primitiva de capital. Mais tarde, nas regiões periféricas, a extração do excedente passa a se dar por meio dos fluxos comerciais, dentro dos mecanismos de transferência de valor já observados, da expansão do capital que conduz à extração da mais-valia localmente, através dos investimentos diretos estrangeiros, e da desregulamentação interna e externa dos fluxos de capitais.

Esses elementos condicionantes da dependência provocam uma forte saída estrutural de recursos, levando a recorrentes problemas de estrangulamento externo e restrições externas ao crescimento. A única maneira que a acumulação de capital interna à economia dependente tem para prosseguir seria aumentar a sua produção de excedente. Assim, ainda que uma parcela crescente desse excedente seja apropriada e, portanto, acumulada, externamente, o restante (a partir da taxa de lucro interna) pode sustentar uma dinâmica de acumulação interna, mesmo que restringida e dependente. A forma associada à condição de dependência para elevar a produção de valor é a superexploração da força de trabalho, o que implica o acréscimo da proporção excedente/gastos com força de trabalho, ou a elevação da taxa de mais-valia, seja por arrocho salarial e/ou extensão da jornada de trabalho, em associação com aumento da intensidade do trabalho.

Ou seja, os condicionantes da dependência colocam uma maciça transferência de valor produzido na periferia que é apropriado no centro da acumulação mundial, e a dinâmica capitalista na periferia é garantida pela superexploração da força de trabalho, ao invés de bloquear esses mecanismos de transferência de valor.

Marini (1977, p. 37) resume o processo:

lo que aparece claramente, pues, es que las naciones desfavorecidas por el intercambio desigual no buscan tanto corregir el desequilibrio entre los precios y el valor de sus mercancías exportadas (lo que implicaría un esfuerzo redoblado para aumentar la capacidad productiva del trabajo), sino más bien compensar la pérdida de ingresos generados por el comercio internacional, através del recurso a una mayor explotación del trabajador.

Com essa dinâmica de acumulação de capital, o capitalismo dependente pode crescer, contornando sua restrição externa. ${ }^{15}$ Entretanto, com esse 
quadro, fica fácil entender como essa dinâmica traz consigo as conseqüências inevitáveis da dependência: distribuição regressiva da renda e da riqueza, associada a uma marginalidade e violência crescentes.

A superexploração da força de trabalho não coloca, em princípio, empecilhos para a acumulação interna de capital, ao restringir o consumo da força de trabalho, porque sua dinâmica de realização pode depender do mercado externo e/ou de um padrão de consumo que privilegie as camadas média e alta da população. Neste último caso, entretanto, o incremento dos lucros pode ser direcionado não como demanda interna (sem contrapartida de produção interna), mas orientado para aumento de importações, seja de bens de consumo para essas camadas da população, seja para meios de produção necessários para a acumulação. Tanto um caso quanto o outro complexificam os déficits estruturais de balanço de pagamentos, formas de manifestação dos mecanismos de transferência de valor. Logo, a manutenção de taxas de crescimento sustentadas na periferia recoloca de forma ampliada os seus condicionantes restritivos. A condição de dependência é estrutural (própria da lógica de acumulação mundial) e tende a se aprofundar, justamente porque esses condicionantes são reforçados por essa própria lógica.

A essa perspectiva teórica da dependência são associadas erroneamente ao menos duas teses que lhe são estranhas. Por um lado, afirma-se que essa perspectiva supervaloriza os fatores externos (de dependência), em detrimento dos fatores internos. Ao contrário, se, de fato a dependência é um fenômeno externo, suas manifestações e arranjos internos não possuem papel secundário. A aliança e o conflito entre as classes internas, sem desconsiderar a adesão destas à ideologia e aos projetos das classes externas, assim como a luta política que é correlata, são determinantes, ${ }^{16}$ por exemplo, na opção de inserção externa passiva dos países latino-americanos nas últimas décadas. A implementação das políticas neoliberais de abertura externa e desregulamentação dos mercados, que aprofundam a dependência, pode ser entendida como fruto de uma conformação entre os interesses da classe dominante da região e os imperativos político-ideológicos do centro da economia mundial, implícitos no Consenso de Washington.

Por outro lado, também é atribuído erroneamente à teoria da dependência o que se chama de estagnacionismo. Afirma-se que, a partir dos condicionantes da dependência (restrição e estrangulamentos externos), a econo- 
mia dependente não teria como crescer, definindo uma tendência à estagnação crônica. Isso, como visto, é falso. Afirmar que subdesenvolvimento e desenvolvimento são elementos de um mesmo processo contraditório de acumulação de capital ${ }^{17}$ não significa que a economia dependente não possa crescer, mas que, quanto mais cresce, no alicerce da superexploração da força de trabalho, mais aguça as diferenças específicas do capitalismo central. Dessa forma, em situação de dependência, maior desenvolvimento capitalista, com o crescimento da economia dependente, implica maior dependência, ${ }^{18}$ o que não é sinônimo de estagnação.

A teoria da dependência, assim entendida, em nada se parece com a abordagem da interdependência presente em Cardoso e Faletto (1970). Entender a relação da economia periférica com a economia mundial enquanto interdependência significa defender a possibilidade de um "desenvolvimento" capitalista associado. Para essa perspectiva, seria possível um "desenvolvimento" capitalista periférico, associado a regimes políticos liberais e democráticos, que amenizasse os efeitos da dependência com políticas sociais compensatórias e conseguisse uma certa elevação do emprego nas fases de crescimento do ciclo mundial. Para esse pensamento, os inimigos do "desenvolvimento" periférico seriam as forças internas, que impediriam a economia periférica de aproveitar as oportunidades de associação com o ciclo econômico do centro sistêmico, a saber, o populismo e o corporativismo. ${ }^{19}$

Qual é a proposta de associação com o centro capitalista? Uma vez que este tem a possibilidade de exportar capitais, em determinadas conjunturas cíclicas, caberia à periferia oferecer condições para o crescimento desse fluxo de capital externo, nos momentos favoráveis da conjuntura mundial, que teria duas funções básicas. Por um lado, o capital externo superaria a escassez de divisas que caracteriza a periferia. Por outro, sob a forma de investimento direto, não só financiaria o crescimento econômico, como seria portador de inovações tecnológicas necessárias para o choque de produtividade, que, em conjunto com as políticas sociais compensatórias, completaria o “jardim do Éden” periférico, possibilitando elevação dos padrões de vida e redução das desigualdades. Restaria à periferia implementar a abertura e a desregulamentação dos mercados para atrair esse capital externo. ${ }^{20}$ Desenvolvimento capitalista associado e neoliberalismo são termos distintos para uma mesma proposta. Como a década de 1990 é considerada "mais do que 
perdida" para a economia latino-americana, justamente por conta da aplicação desse tipo de perspectiva, isso dispensa maiores comentários críticos a essa interpretação da interdependência.

O importante a reter é que, dados os condicionantes histórico-estruturais da dependência, reforçados pela própria dinâmica de acumulação mundial, a resposta periférica para o desenvolvimento capitalista está baseada na superexploração da força de trabalho e, conseqüentemente, na distribuição regressiva da renda e da riqueza, assim como no aprofundamento dos problemas sociais.

\subsection{Dialética do capital fictício:}

(dis)funcionalidade do capital fictício para a acumulação

A essa dinâmica de acumulação de capital na periferia agrega-se, com maior força na atualidade, o desenvolvimento e a dialética do capital fictício.

O capital fictício pode ser entendido como um desdobramento (complexificação) do capital portador de juros. O desenvolvimento da autonomização das formas do capital e a separação entre o capital-propriedade e o capital-função permitem o aparecimento do que Marx chamou de mercadoria-capital. ${ }^{21}$ É possível, a partir disso, que o capitalista-proprietário abdique de utilizar seu capital-dinheiro como meio para inserir-se no processo de produção de mercadorias e empreste seus recursos para outro capitalista que pretenda fazê-lo. Esse capital-função entrará no processo de circulação do capital, comprando meios de produção e contratando força de trabalho, produzindo mercadorias com um valor acrescido, um excedente ou mais-valia, e vendendo essas mercadorias. A partir do resultado obtido, com a realização da mais-valia, esse capital-função poderá pagar o seu empréstimo, acrescido dos juros (remuneração do capital-propriedade, ou seja, do capital portador de juros), e mesmo assim poderá apropriar-se de um lucro. Juros constituem o rendimento do capital-propriedade, enquanto lucro constitui o rendimento do capital-função.

O desenvolvimento desse processo faz com que todo rendimento obtido a partir de uma determinada taxa de juros apareça como o resultado da propriedade de um capital, isto é, da propriedade de um capital portador de juros, exista ele ou não. Do ponto de vista do indivíduo, trata-se realmente de capital para o seu proprietário, dado que ele consegue um rendimento 
em determinado período. A partir dessa remuneração, para uma certa taxa de juros, obtém-se um montante de capital através do que se chama capitalização. ${ }^{22}$ Entretanto, do ponto de vista da totalidade da economia capitalista, esse capital é fictício, uma vez que tem como base a participação de títulos de crédito em rendimentos futuros, que podem nem se realizar; além do que o mesmo título pode ser revendido inúmeras vezes, a partir da mesma taxa de juros, formando várias propriedades (direitos de participação) com base em apenas um montante de capital inicial, que pode nem completar o seu processo de circulação. ${ }^{23}$

Assim, do ponto de vista individual, trata-se de capital para seu proprietário, mas do ponto de vista do capital global é fictício. Entretanto, o caráter fictício desse capital não lhe retira influência sobre a acumulação de capital; sua lógica interfere na dinâmica da acumulação. Essa interferência é, como a própria dinâmica capitalista, contraditória, dialética. A dialética do capital fictício está relacionada à sua (dis)funcionalidade para o processo de acumulação de capital.

Como todo o processo de autonomização das formas do capital, o capital fictício apresenta uma funcionalidade para a acumulação de capital. A sua centralização por parte do capital bancário ${ }^{24}$ permite o funcionamento de atividades produtivas que, de outra forma, teriam de esperar muito tempo para serem implementadas. Além disso, essa forma autonomizada promove a liberação de capital para o processo produtivo, uma vez que recursos que seriam gastos para a compra de meios de produção e força de trabalho, assim como para cobranças de mercadorias vendidas e ainda não pagas, não precisam mais se ocupar dessas funções, permitindo ao capital produtivo individual ocupar-se apenas do processo produtivo. ${ }^{25}$

Isso permite a maior acumulação global de capital, a redução do tempo de rotação do mesmo e, portanto, o aumento da taxa de lucro por período. Como visto no início, a rotação do capital, reduzindo o tempo de seu ciclo, é uma resposta da economia capitalista à redução da taxa de lucro, imposta por seu próprio funcionamento de crise cíclica. O capital fictício, nesse momento, pode contribuir com essa resposta do capital para sua própria crise. ${ }^{26}$

Todavia, o capital fictício não produz apenas benesses para a dinâmica de acumulação de capital. Ele possui a funcionalidade descrita, mas possui uma disfuncionalidade que não pode ser negligenciada. O capital fictício, 
do ponto de vista individual, por si só não é capaz de produzir valor excedente, mais-valia, pelo simples fato de que não entra no processo produtivo. O que ele faz é possibilitar/facilitar o financiamento do capital produtivo, em alguns momentos específicos. A sua lógica diz respeito à apropriação do excedente (via juros), não à sua produção, embora ele contribua indiretamente - via rotação do capital global — para o aumento da acumulação. Assim, se a lógica da apropriação de mais-valia é alastrada/expandida, em detrimento da produção do excedente, uma parcela cada vez maior do capital global procurará apropriar-se de um valor que está sendo produzido cada vez menos. O resultado final é a redução da taxa de lucro e o aprofundamento do comportamento cíclico da crise.

Por um lado, a funcionalidade do capital fictício permite o prolongamento da fase ascendente do ciclo, possibilitando a redução do tempo de rotação do capital global e a elevação da taxa de lucro. Por outro lado, quando sua lógica individual de apropriação se expande, a fase descendente (crise) do ciclo também é aprofundada. A disfuncionalidade do capital fictício amplia as potencialidades da crise. A dialética do capital fictício, com sua (dis)funcionalidade, complexifica/amplia a tendência cíclica do processo de acumulação de capital.

Qual é a relação dessa característica, inerente ao funcionamento do modo de produção capitalista, com a possibilidade de desenvolvimento capitalista na periferia, baseada na superexploração da força de trabalho?

A superexploração da força de trabalho por arrocho salarial e/ou elevação da jornada e da intensidade do trabalho faz com que se produza uma maior massa de mais-valia em relação ao valor criado no processo produtivo, aumentando a taxa de mais-valia. Quando esse maior excedente é apropriado em maior proporção pelo capital produtivo, são criadas as condições para a acumulação de capital acelerada, "virtuosa". ${ }^{27}$ Por outro lado, quando a lógica de apropriação do excedente se amplia, sob a lógica do capital fictício, que não contribui diretamente na produção desse excedente, a maisvalia passa a ser apropriada cada vez mais em termos financeiros do que produtivos. Maior remuneração financeira (manifestada em altas taxas de juros, por exemplo) do que taxa de lucro do capital produtivo incentiva os capitais individuais a se transferirem para essa primeira esfera, a operar segundo a lógica do capital fictício. Isso deprime ainda mais a taxa de lucro do 
capital produtivo, uma vez que se tem menor produção de excedente, definindo um círculo vicioso de acumulação de capital travada.

Assim, a acumulação de capital "virtuosa" expande as fases ascendentes do ciclo, impulsionadas pela funcionalidade do capital fictício, enquanto a acumulação de capital travada aprofunda a fase descendente - crise complexificada pela disfuncionalidade do capital fictício.

Essa dialética do desenvolvimento periférico permite entender, por exemplo, o que ocorreu na economia da América Latina durante os anos 1990. Nos poucos períodos em que o capital fictício foi funcional à acumulação de capital, acelerando sua rotação e financiando investimentos produtivos, as economias apresentaram um leve crescimento. Entretanto, durante a maior parte do período, a região apresentou uma dinâmica de acumulação de capital travada, de forma que a elevação da taxa de mais-valia por intermédio da superexploração da força de trabalho não se transformou em maior ritmo de acumulação de capital, porque a apropriação financeira pelo capital fictício reduziu as taxas de lucro do capital produtivo, principal incentivo para a acumulação de capital.

A década mais do que perdida para a região, como ficou conhecido o período, combinou superexploração da força de trabalho com acumulação de capital travada.

\section{Alternativas de desenvolvimento e política eConômica}

Resta o questionamento: o que fazer? Se a condição de dependência implica a superexploração da força de trabalho como única forma de acumulação de capital interno, é possível uma trajetória de crescimento para a periferia que se associe a uma melhora do perfil distributivo? Qual o papel da política econômica nesse contexto? Uma política econômica "adequada" permite resolver os problemas estruturais das economias periféricas, isto é, sua situação de dependência?

De fato, a estratégia e a política econômica podem interferir no grau de dependência das economias periféricas em relação ao centro da economia mundial. A implementação das políticas neoliberais, sob a batuta ideológica do Consenso de Washington, aprofundou a condição de dependência ao longo dos anos 1990. O programa neoliberal se caracteriza pela afirmação 
de uma estabilização macroeconômica (controle inflacionário e fiscal) como precondição, ora com políticas ortodoxas, e em alguns momentos até com políticas heterodoxas (de regime cambial fixo, ou "quase fixo", por exemplo). Além disso, o programa afirma que a retomada dos investimentos e do crescimento só é possível após uma fase de reformas estruturais, que englobaria: abertura comercial e financeira, desregulamentação dos mercados (principalmente o de trabalho e o financeiro), amplo processo de privatização e liberalização dos preços.

O que os anos 1990 mostraram é que, em primeiro lugar, as reformas neoliberais não garantem a retomada do crescimento, ao contrário, amplificam a trajetória de estagnação, instabilidade e crise. Em segundo lugar, as reformas neoliberais aprofundaram o grau de dependência das economias periféricas, por reduzirem a competitividade dos produtos exportados pelos países periféricos, em relação aos produtos importados, o que amplia a deterioração dos termos de troca, por elevarem a dependência das economias em relação ao fluxo internacional de capitais (elevação da fragilidade financeira das contas externas) e por diminuírem a capacidade de resistência dessas economias a choques externos, dentro de um sistema financeiro internacional instável (aumento do grau de vulnerabilidade externa). ${ }^{28}$

Apesar da difusão ideológico-política de que a estratégia neoliberal seria a única inserção econômica possível, alternativas de desenvolvimento e instrumentalização da política econômica, que revertem o aprofundamento da condição de dependência, ${ }^{29}$ existem.

Várias são as propostas alternativas, nem sempre congruentes entre si. ${ }^{30}$ Mesmo entre os defensores da teoria ortodoxa, pouca discordância existe sobre o fato de que as altas taxas reais de juros impedem o crescimento. O debate se constrói, fundamentalmente, sobre as razões dessa alta taxa de juros. Para a teoria convencional, isso ocorreria em razão da elevada dívida pública. Os mercados acabariam exigindo altas taxas de juros para refinanciar os papéis dessa dívida. ${ }^{31}$ Ao contrário disso, as elevadas taxas de juros das economias periféricas são originadas da alta vulnerabilidade externa de suas economias. Para atrair os capitais externos, necessários para financiar as contas externas desequilibradas, é preciso fornecer um diferencial de juros, em relação às taxas internacionais, de montante considerável. 
A redução das taxas de juros - sem nenhuma outra medida — provocaria fuga de capitais e forte desvalorização do câmbio. É por isso que qualquer alternativa de política econômica deve começar por medidas que impliquem o controle (qualitativo e/ou quantitativo) do fluxo de capitais. Com isso seria possível reduzir as taxas de juros, freando o crescimento do estoque da dívida pública, reduzindo a necessidade do superávit primário das contas públicas. $\mathrm{O}$ alívio das contas públicas seria completado pela redução do estoque da dívida atrelado a variações cambiais. Nesse conjunto de medidas pode estar incluída - dentro de um programa de maior ruptura com a estratégia neoliberal - a redução do grau de abertura externa (comercial, financeira, cambial e produtiva), de forma a reduzir o grau de vulnerabilidade externa.

Ainda nesse sentido, no front interno é necessário o recuo nos processos de flexibilização e desregulamentação dos mercados de trabalho e financeiro. No que se refere a este último, os objetivos seriam a redução no grau de autonomia do setor privado para a oferta de moeda e o redirecionamento do crédito para financiamento da produção.

A idéia de um programa de ruptura nesse sentido seria alterar o padrão de consumo da economia: (i) privilégio do mercado interno que se baseie no consumo de massas; ${ }^{32}$ (ii) desestímulo ao padrão de acumulação elitista que caracteriza as economias periféricas de "banquetes" exclusivos de bens de consumo de luxo para as elites, geralmente produtos importados, e/ou de bens de consumo supérfluos para a classe média. ${ }^{33}$

Com esse programa de ruptura seria obtida a redução do grau de vulnerabilidade externa e, portanto, de dependência da economia, assim como do grau de exploração da força de trabalho. Entretanto, um programa econômico de ruptura, por maior que seja essa ruptura do ponto de vista das medidas econômicas, não consegue extinguir a condição dependente e a exploração da força de trabalho, características intrínsecas da lógica mundial de acumulação capitalista. Isso nos remete novamente à questão da dialética do desenvolvimento periférico.

O padrão de acumulação travada, com aumento da taxa de mais-valia, em virtude da superexploração da força de trabalho, mas com apropriação do excedente em maiores proporções financeiras, não permite o crescimento da economia. A redução do grau de vulnerabilidade externa e a regulamentação financeira interna permitiriam uma maior apropriação do exce- 
dente pelo capital produtivo e, portanto, um maior ritmo de acumulação e crescimento da economia. É possível conceber, dessa forma, um programa econômico alternativo que garanta um padrão de acumulação "virtuosa", mas virtuosa apenas para o capital "nacional”, pois continua baseando-se na superexploração da força de trabalho e na concentração de renda e riqueza.

Não é sobre essas bases que se deve construir um programa econômico alternativo popular. Existem duas formas de reduzir o grau de dependência. A primeira implica a redução da superexploração da força de trabalho, podendo redundar em um limite para o crescimento da economia, uma vez que os ganhos obtidos com a redução da transferência de valores para o centro da acumulação mundial seriam apropriados mais pela classe trabalhadora e menos pela classe capitalista, restringindo o ritmo de acumulação por esse lado. Se não fossem criadas condições para a constituição de amplo mercado interno, baseado no consumo das massas, o crescimento da economia seria restringido. Essa estratégia, claramente antineoliberal, traria consigo fortes lutas políticas internas (com as classes dominantes locais) e externas (com as classes dominantes internacionais e a lógica mundial capitalista), em função da reversão dos condicionantes da dependência.

A outra estratégia de combate à condição de dependência seria simplesmente contestar a própria exploração da força de trabalho como base da produção de excedente, isto é, uma estratégia que fosse além do antineoliberalismo e se propusesse anticapitalista. Se as relações, lutas e contradições explicitadas pela primeira estratégia já seriam fortes, para esta estratégia de ruptura com a lógica capitalista o conflito seria amplificado. Para isso, o respaldo popular para a proposição desse tipo de estratégia é muito mais importante.

O fundamental a destacar aqui é que as duas estratégias, a antineoliberal e a anticapitalista, não são necessariamente excludentes. É possível defender uma estratégia antineoliberal tendo como projeto final um programa socialista. Entretanto, as duas estratégias tampouco são diretamente complementares. O projeto de acumulação de capital "virtuosa”, em prol do capital "nacional", pode perfeitamente assumir-se como antineoliberal, mas, justamente porque depende da exploração da força de trabalho para sustentar a taxa de mais-valia e o ritmo da acumulação, não pode ser anticapitalista; não pode aliar-se com um programa de fim da exploração da força de trabalho. 


\section{CONCLUSÕES}

As respostas do capitalismo para tentar recuperar-se da crise nos últimos 40 anos impuseram aos países da periferia da economia mundial um acirramento da dependência. A única possibilidade de desenvolvimento capitalista periférico parte da superexploração da força de trabalho como forma de elevar as taxas internas de mais-valia. Dependendo da forma como for apropriada essa maior massa de mais-valia, o capitalismo periférico pode assumir uma dinâmica de acumulação travada ou "virtuosa".

A estratégia de desenvolvimento e a política econômica podem aprofundar o grau dessa dependência, ao elevar a vulnerabilidade externa das economias, como acontece com programas neoliberais, ou reduzir o grau dessa dependência e vulnerabilidade, ao restringir o grau de abertura externa dessas economias periféricas. Obviamente, isso não é obtido com medidas tópicas de administração de certas variáveis (taxa de câmbio, oferta de crédito, taxa de juros etc.), mas a partir de políticas que, por exemplo, reduzam o grau de abertura externa, comercial e financeira, nas economias latino-americanas da atualidade, elevem a capacidade de controle cambial, tendo em vista os problemas nas contas externas, e revertam o atual grau de flexibilização e desregulamentação dos mercados. A política econômica pode ainda promover um processo redistributivo interno às economias periféricas, reduzindo a característica estrutural de concentração de renda e riqueza.

Uma proposição desse tipo já enfrentaria resistências político-ideológicas internas e externas não desprezíveis. Entretanto, essa estratégia não pode, por si só, acabar com a condição de dependência e exploração capitalista da força de trabalho.

De fato, qualquer que seja a administração da política econômica, ela não tem como resolver os problemas estruturais colocados pela situação de dependência, uma vez que esta é parte constituinte da própria lógica de acumulação de capital em escala mundial, a não ser que essa própria lógica capitalista seja modificada de uma ou outra forma. Acreditar no contrário, ou seja, que tudo é uma questão de implementar uma política econômica "correta", significa conceber a dicotomia desenvolvimento versus subdesenvolvimento como mera diferenciação quantitativa, sem relação com a dinâmica de acumulação de capital mundial, e como fenômenos meramente antagônicos e não complementares. 
O que a política econômica pode fazer, no máximo, é aumentar os graus de liberdade no seu manejo, dentro da condição dependente, mas não desestruturar essa condição. Escapar da dialética do desenvolvimento capitalista, mantendo, ou, no máximo, reformando o caráter capitalista, significa cair no moto-perpétuo das políticas compensatórias.

\section{NOTAS}

1. Mendonça (1990) faz uma excelente análise, não só da crise capitalista dos anos 1970, mas também das teorias que afirmaram o fim das crises cíclicas e a capacidade de controle do sistema por intermédio de políticas econômicas corretas (SIC).

2. Mais detalhes sobre a interpretação de Marx para o fenômeno das crises podem ser encontrados em Marx (1985, v. 4, cap. 15), assim como uma tentativa de delimitar conteúdo, causa e formas de manifestação do fenômeno é feita em Carcanholo (1997).

3. Essa forma de interpretar a crise dos anos 1970, a partir de uma interpretação marxista, é encontrada em diversos autores, ainda que com diferentes abordagens. Além de Mendonça (1990), podem-se consultar Antunes (2000), Mandel (1977), Romo (1988), Harvey (1982), entre outros.

4. Maddison (2001), por exemplo, apresenta uma rica série de dados sobre a economia mundial desde o século XIX. Entretanto, especificamente no capítulo 3, esse autor faz uma periodização para a segunda metade do século XX que engloba os seguintes períodos: 1950-1973, 1973-1983, 1983-1993 e 1994-1998. Obviamente, em função da crise da economia mundial nos anos 1970, os dados mostram a retração para o período 19731983. Essa forma de dividir os períodos, no entanto, sugere, para um leitor mais desavisado, que a crise se iniciaria em 1973.

5. A taxa de crescimento do conjunto de países da OCDE em 1974 foi de-0,2\% (Mendonça, 1990, p. 44).

6. Um excelente tratamento das origens e características da desordem econômica internacional, a partir da crise do sistema de Bretton Woods, pode ser encontrado em Block (1980). Além disso, uma vasta bibliografia interpreta essa turbulência na economia mundial a partir da crise do padrão monetário dólar-ouro e do nascedouro do padrão monetário dólar-flexível. Essa literatura, que avança inclusive na análise da posterior política de brutal elevação das taxas de juros americanas em 1979, dentro do que se convencionou chamar de "diplomacia do dólar forte", pode ser encontrada em Tavares (1997), Tavares e Melin (1997), Mello (1997), Medeiros e Serrano (1999), Teixeira (2000) e Serrano (2002).

7. A relação entre a rotação do capital e a taxa de lucro pode ser encontrada em Muls e Carcanholo (1997).

8. A categoria capital fictício é tratada mais adiante. Desde já, uma análise mais aprofundada de sua dinâmica e atualidade pode ser encontrada em Marx (1985, seção quinta do 
livro III) e desenvolvida em Carcanholo e Nakatani (1999). Do ponto de vista da expansão concreta do que se convencionou chamar de globalização financeira, esse movimento também pode ser entendido a partir da perspectiva da constituição de um padrão monetário internacional do tipo dólar flexível, conforme nota anterior.

9. Os dados apresentados em Dumenil e Levy (2004) demonstram que, em 2000, "a renda financeira que os EUA retiraram de suas relações com o resto do mundo foi superior ao conjunto dos lucros de suas próprias sociedades em território americano" (p. 24). Os mesmos dados mostram que essa proporção é crescente desde 1950 e acelera seu crescimento no final dos anos 1970 (início dos anos 1980), justamente quando o neoliberalismo se aprofunda e que a América Latina tem um papel de destaque nesse processo.

10. A nomenclatura para essa situação varia de acordo com as circunstâncias/conjunturas político-econômicas de cada momento. As economias nessa situação já foram chamadas de subdesenvolvidas, em vias de desenvolvimento, periféricas, "mercados emergentes", dentre outros neologismos.

11. No contexto de formação da Cepal, as políticas econômicas defendidas como "corretas" estavam ligadas ao projeto industrializante de substituição de importações.

12. Referimo-nos aqui à Teoria da Dependência na sua versão marxista, como pode ser encontrada em Marini (1977), Santos (1970) e Santos (2000).

13. Santos (1970) identificou três formas históricas de dependência: (i) colonial; (ii) financeiro-industrial; e (iii) tecnológico-industrial do pós-guerra, sob a liderança das empresas transnacionais. A identificação da atualidade neoliberal como uma nova forma histórica de dependência financeira poderia ser tematizada.

14. A influência da teoria marxista do imperialismo é inegável, uma vez que o subdesenvolvimento é uma conseqüência e uma parte do processo de concentração/centralização do capital, em escala mundial.

15. A resposta periférica à sua condição dependente é mais atual do que nunca, no sentido de que, "nas economias subdesenvolvidas, os ganhos de produtividade foram obtidos principalmente através do aumento nas taxas de desemprego, da jornada de trabalho e da precarização dos trabalhadores" (Nakatani, 2002, p. 1).

16. Nesse ponto específico não se pode desconsiderar que, em cada país/região periférico, as condições de formação e desenvolvimento das classes dominantes locais são específicas, de forma que é possível tanto a constituição de uma classe dominante local altamente vinculada a interesses externos, até uma associação mais explícita entre as duas. As especificidades de formação e desenvolvimento também são importantes no que diz respeito à classe trabalhadora.

17. É nisso, basicamente, que consiste a tese do desenvolvimento do subdesenvolvimento segundo Frank (1980). Sobre isso, Marini (1992, p. 88) afirma que "o subdesenvolvimento não é uma etapa que precede o desenvolvimento, ele é um produto do desenvolvimento do capitalismo mundial; nesse sentido, ele corresponde a uma forma específica de capitalismo, que se apura em função do próprio desenvolvimento do capitalismo”. 
18. O caso do recente "milagre" asiático é característico. Embora esses países tenham optado por maior soberania em suas inserções externas ativas, isso não resolveu o caráter dependente de suas economias, relembrado e reposto pela crise de 1997.

19. Assim como nas origens da teoria do desenvolvimento, quando o subdesenvolvimento era mero estágio para a modernidade, a culpa pela situação de subdesenvolvimento seria responsabilidade única e exclusiva de "escolhas" erradas dos próprios países dependentes.

20. A proposta da Nova Cepal, expressa na Reforma das reformas e Transformação produtiva com eqüidade, guarda insignificante distância com essa perspectiva, como pode ser constatado em Ocampo (1999), Ffrench-Davis (1999), Cepal (1990) e Cepal (1998).

21. Marx (1985, livro III, cap. 21) desenvolve essas categorias dentro da temática do capital portador de juros. Especificamente sobre o capital fictício, os capítulos 25, 27 e 29 são a referência principal.

22. Capitalização seria, assim, a formação do capital fictício, a partir de um determinado rendimento que, aplicando-se à taxa de juros vigente, forma um montante de recursos (capital), independentemente do fato de esse capital existir ou não (Marx, 1985, v. V, p. 5).

23. O caráter autônomo da circulação do capital fictício é explicitado quando a cotação dos papéis supera o valor do capital industrial em que foi transformado o capital-dinheiro, e oscila com independência desse capital industrial em movimentos puramente especulativos.

24. Que não precisa se restringir à instituição financeira bancária. Instituições financeiras não bancárias podem perfeitamente cumprir essa função, como ocorre na atualidade. A categoria capital bancário, nesse sentido, não pode ser confundida com a instituição concreta banco.

25. O capital comercial autonomizado permite o mesmo no que se refere à comercialização das mercadorias produzidas. Aliás, o capital portador de juros e o capital fictício, enquanto operados pelo capital bancário, podem ser entendidos como desdobramentos dialéticos do capital de comércio de dinheiro.

26. “O período recente da expansão americana só foi possível através da transferência de mais-valia produzida em todo o mundo e pela gigantesca expansão do capital fictício, o que mascarou a pressão decrescente da taxa de lucro" (Nakatani, 2002, p. 1).

27. Obviamente, o "virtuoso" aqui diz respeito aos interesses do capital, que aumenta o ritmo de sua acumulação com maiores taxas de lucro. Do ponto de vista da força de trabalho, sua superexploração redunda, como visto, em distribuição regressiva da renda e da riqueza e na ampliação das mazelas sociais.

28. Para uma discussão mais aprofundada dos efeitos da estratégia neoliberal de desenvolvimento na América Latina, ver Cano (2000) e Carcanholo (2005). No que se refere ao caso brasileiro, alguns autores poderiam sustentar que o governo Lula seria um contraexemplo, uma vez que, mesmo mantendo a estratégia neoliberal, a economia brasileira apresentou no início do século XXI uma retomada do crescimento. Entretanto, isso se 
deve muito mais a uma considerável melhora no cenário externo (liquidez abundante, crescimento da economia mundial e elevação dos preços das commodities, principais produtos exportados pelo país), e não a uma ruptura do governo Lula com a estratégia neoliberal; ao contrário, esta última foi aprofundada por esse governo (Filgueiras e Gonçalves, 2007).

29. E, portanto, reduzem a necessidade de ampliação da superexploração da força de trabalho como forma de garantir a acumulação de capital interna à economia dependente. Logo, as mazelas sociais decorrentes da superexploração da força de trabalho poderiam ser reduzidas.

30. Elas podem ser encontradas, por exemplo, em Gonçalves (2003), Paula (2003) e Huerta (2004).

31. O argumento convencional acaba desconsiderando, com isso, a relação mais óbvia, a partir da qual o estoque da dívida pública cresce justamente porque as altas taxas de juros acabam corrigindo esse estoque. Maiores detalhes sobre a dinâmica da dívida pública podem ser encontrados em Painceira e Carcanholo (2004).

32. Uma precondição para esse padrão de consumo é a redução da exploração da força de trabalho e a distribuição de renda e riqueza da economia, de forma a incluir mais pessoas com capacidade de participação nesse mercado interno.

33. Um exemplo de programa de recuperação popular da economia nesse sentido, para o caso argentino, pode ser encontrado em EDI (2004).

\section{REFERÊNCIAS BIBLIOGRÁFICAS}

ANTUNES, R. Os sentidos do trabalho: ensaio sobre a afirmação e a negação do trabalho. 3. ed. São Paulo: Boitempo Editorial, 2000.

BLOCK, F. L. Los Orígenes del Desorden Económico Internacional: la política monetaria internacional de los Estados Unidos, desde la segunda Guerra Mundial hasta nuestros días. México: Fondo de Cultura Económica, 1980.

CANO, W. Soberania e política econômica na América Latina. São Paulo: Unesp, 2000.

CARCANHOLO, M. D. A vulnerabilidade econômica do Brasil: abertura externa a partir dos anos 1990. Aparecida: Idéias \& Letras, 2005.

Formas, conteúdo e causa: uma proposta de interpretação marxista do fenômeno crise. Leituras de Economia Política, Campinas, n. 5, 1997.

CARCANHOLO, R. A.; NAKATANI, P. O capital especulativo parasitário: uma precisão teórica sobre o capital financeiro, característico da globalização. In: ENCONTRO NACIONAL DE ECONOMIA POLÍTICA, 4. Anais. Porto Alegre: Sociedade Brasileira de Economia Política, (http://sites.uol.com.br/carcanholo), 1999.

CARDOSO, F. H.; FALETTO, E. Dependência e desenvolvimento na América Latina. Rio de Janeiro: Zahar, 1970. 
CEPAL. América Latina y El Caribe: políticas para mejorar la inserción en la economía mundial. 2. ed. Santiago: Fondo de Cultura Económica, 1998.

Transformación productiva con equidad: la tarea prioritária del desarrollo de América Latina y el Caribe en los años noventa. Santiago, 1990.

DUMENIL, G.; LEVY, D. O Imperialismo na era neoliberal. Crítica Marxista, Revan, n. 18, maio 2004.

EDI. Argentina: um programa de recuperação popular da economia. Documento dos Economistas de Esquerda - EDI. Revista da Sociedade Brasileira de Economia Política, Rio de Janeiro, n. 14, jun. 2004.

FFRENCH-DAVIS, R. Macroeconomía, Comercio y Finanzas: para reformar las reformas en América Latina. Santiago: CEPAL-McGraw-Hill, 1999.

FILGUEIRAS, L.; GONÇALVES, R. A economia política do governo Lula. Rio de Janeiro: Contraponto, 2007.

FRANK, A. G. Acumulação dependente e subdesenvolvimento: repassando a teoria da dependência. São Paulo: Brasiliense, 1980.

GONÇALVES, R. Política econômica e macrocenários nacionais: 2003-2006. Revista da Sociedade Brasileira de Economia Política, Rio de Janeiro, n. 12, jun. 2003.

HARVEY, D. Los Limites Del Capitalismo y La Teoría Marxista. México: Fondo de Cultura Económica, 1982.

HUERTA, A. La Economía Política Del Estancamiento. México: Editorial Diana, 2004.

MADDISON, A. The world economy: a millennial perspective. Development Centre Studies, Paris: OECD, 2001.

MANDEL, E. La Crisis, 1974-1980: interpretación marxista de los hechos. México: Série Popular Era, 1977.

MARINI, R. M. América Latina: dependência e integração. São Paulo: Brasil Urgente, 1992.

- Dialéctica de la Dependencia. 3. ed. México: Série Popular Era, 1977.

MARX, K. O Capital: crítica da economia política. 5 v. São Paulo: Nova Cultural, 1985.

MEDEIROS, C. A.; SERRANO, F. Padrões monetários internacionais e crescimento. In: FIORI, J. L. (Org.). Estados e moedas no desenvolvimento das nações. Petrópolis: Vozes, 1999.

MELLO, J. M. C. A contra-revolução liberal-conservadora e a tradição crítica latino-americana: um prólogo em homenagem a Celso Furtado. In: TAVARES, M. C.; FIORI, J. L. (Org.) Poder e dinheiro: uma economia política da globalização. Petrópolis: Vozes, 1997.

MENDONÇA, A. A crise econômica e a sua forma contemporânea. Lisboa: Editorial Caminho, 1990.

MULS, L.; CARCANHOLO, M. D. Revolução tecnológica e acumulação de capital: capitalismo sem trabalho? In: ENCONTRO NACIONAL DE ECONOMIA, 25. Anais. Salvador: Anpec, 1997.

NAKATANI, P. A crise atual do sistema capitalista mundial. In: ENCONTRO NACIONAL DE ECONOMIA POLÍTICA, 7. Anais. Curitiba: Sociedade Brasileira de Economia Política, 2002. 
OCAMPO, J. A. La Reforma del Sistema Financiero Internacional: um debate em marcha. Santiago: Fondo de Cultura Económica - CEPAL, 1999.

PAINCEIRA, J. P.; CARCANHOLO, M. D. A ortodoxia neo-companheira: vulnerabilidade externa, política econômica e determinação dos fluxos de capitais. In: ENCONTRO NACIONAL DE ECONOMIA POLÍTICA, 9. Anais. Uberlândia: Sociedade Brasileira de Economia Política, 2004.

PAULA, J. A. A economia politica da mudança: os desafios e os equívocos do início do governo Lula. Belo Horizonte: Autêntica, 2003.

ROMO, H. G. Lecciones de economía marxista. México: Fondo de Cultura Económica, 1988.

SANTOS, T. dos. A teoria da dependência: balanço e perspectivas. Rio de Janeiro: Civilização Brasileira, 2000.

The structure of dependence. American Economic Review, Nova York, 1970.

SERRANO, F. Do ouro imóvel ao dólar flexível. Economia e Sociedade, v. 11, n. 2, 19, p. 237 253, jul./dez. 2002.

TAVARES, M. C. A retomada da hegemonia norte-americana. In: TAVARES, M. C.; FIORI, J. L. (Org.). Poder e dinheiro: uma economia política da globalização. Petrópolis: Vozes, 1997.

; MELIN, L. E. Pós-escrito 1997: a reafirmação da hegemonia norte-americana. In: TAVARES, M. C.; FIORI, J. L. (Org.). Poder e dinheiro: uma economia política da globalização. Petrópolis: Vozes, 1997.

TEIXEIRA, A. O Império contra-ataca: notas sobre os fundamentos da atual dominação norte-americana. Economia e Sociedade, Campinas, n. 15, p. 1-13, dez. 2000. 